\title{
Role of long-chain hydrocarbons in the aggregation behaviour of Harmonia axyridis (Pallas) (Coleoptera: Coccinellidae)
}

\author{
Delphine Durieux $^{\mathrm{a}, *}$, Christophe Fischer ${ }^{\mathrm{b}}$, Yves Brostaux ${ }^{\mathrm{c}}$, John J. Sloggett ${ }^{\mathrm{d}}$, Jean-Louis Deneubourg ${ }^{\mathrm{e}}$, \\ Axel Vandereycken ${ }^{\mathrm{a}}$, Emilie Joie ${ }^{\mathrm{a}}$, Jean-Paul Wathelet ${ }^{\mathrm{f}}$, Georges Lognay ${ }^{\mathrm{b}}$, Eric Haubruge ${ }^{\mathrm{a}}$, \\ François J. Verheggen ${ }^{a}$ \\ ${ }^{a}$ Functional and Evolutionary Entomology, Gembloux Agro-Bio Tech, University of Liege, Passage des Déportés 2, 5030 Gembloux, Belgium \\ ${ }^{\mathrm{b}}$ Unit of Analysis Quality and Risk, Laboratory of Analytical Chemistry, Gembloux Agro-Bio Tech, University of Liege, Passage des Déportés 2, 5030 Gembloux, Belgium \\ ${ }^{\mathrm{C}}$ Applied Statistics, Computer Science and Mathematics, Gembloux Agro-Bio Tech, University of Liege, Avenue de la Faculté 8, B-5030 Gembloux, Belgium \\ d Maastricht Science Programme, Maastricht University, P.O. Box 616, 6200 MD Maastricht, The Netherlands \\ ${ }^{\mathrm{e}}$ Unit of Social Ecology, Université libre de Bruxelles, Campus Plaine - CP 231, B-1050 Brussels, Belgium \\ ${ }^{\mathrm{f}}$ General and Organic Chemistry, Gembloux Agro-Bio Tech, University of Liege, Passage des Déportés 2, 5030 Gembloux, Belgium
}

\section{A R T I C L E I N F O}

\section{Article history:}

Received 15 December 2011

Received in revised form 2 March 2012

Accepted 5 March 2012

Available online $\mathrm{xxxx}$

\section{Keywords:}

Area marking

Overwintering behaviour

Invasive species

Coccinellidae

Contact pheromones

\begin{abstract}
A B S T R A C T
The multicoloured Asian ladybirds, Harmonia axyridis (Pallas), form large aggregations inside dwellings to survive cold winters, causing annoyance to householders due to their abundance, allergenic properties and problems consequent on reflex bleeding. Flight to overwintering sites and macrosite choice of this species is well documented. H. axyridis shows a hypsotactic behaviour and a clear preference for contrasting visual elements. However, how the microsite is selected remains undocumented, although a better understanding of the factors implicated could lead to the development of new control methods for this pest.

In this work, we hypothesised that non-volatile compounds are involved in the microsite choice and aggregation of this beetle. Long chain hydrocarbons were identified at aggregation sites, comprising saturated and unsaturated homologues. An aggregation bioassay was then conducted on overwintering individuals, highlighting the retention capacity of the identified compounds on the tested ladybirds. Additional investigations showed that $H$. axyridis males and females, originating from overwintering sites, deposit a similar blend of molecules while walking. A Y-shaped tube assay revealed that this blend is used by male and female congeners as cue allowing individuals to orientate towards the treated side of the olfactometer. These results suggest the use of two different blends of long chain hydrocarbons by H. axyridis during its aggregative period, the first one to lead conspecifics towards aggregation sites (microsites) and the second to ensure the cohesion of the aggregation. These findings support the potential use of these blends, in association with volatiles, in the design of traps in order to control infestations of this species in dwellings.
\end{abstract}

(c) 2012 Elsevier Ltd. All rights reserved.

\section{Introduction}

The multicoloured Asian ladybird, Harmonia axyridis (Pallas) (Coleoptera: Coccinellidae), originates from south-east Asia. In the 20th century, it was introduced into North America and Europe as a biocontrol agent for aphid and coccid populations (Brown et al., 2011). It was believed that $H$. axyridis would not survive cold

\footnotetext{
* Corresponding author. Tel.: +32 816222 81; fax: +32 81622312 .

E-mail addresses: D.Durieux@ulg.ac.be (D. Durieux), christophe.fischer@ ulg.ac.be (C. Fischer), y.brostaux@ulg.ac.be (Y. Brostaux), johnsloggett@yahoo.co.uk (J.J. Sloggett), jldeneub@ulb.ac.be (J.-L. Deneubourg), a.vandereycken@ulg.ac.be (A. Vandereycken), ejoie@ulg.ac.be (E. Joie), jp.wathelet@ulg.ac.be (J.-P. Wathelet) georges.lognay@ulg.ac.be (G. Lognay), E.Haubruge@ulg.ac.be (E. Haubruge), fverheggen@ulg.ac.be (F.J. Verheggen), fverheggen@ulg.ac.be (F.J. Verheggen).
}

winters (McClure, 1987); however it is now a well-established invasive species in both regions (Brown et al., 2011). One possible reason for this is that $H$. axyridis found a solution to the problem of cold winters by aggregating inside buildings and dwellings during those unfavourable conditions (McClure, 1987; Labrie et al., 2008).

Nalepa et al. (2005) suggested a five-step overwintering aggregation behaviour for $H$. axyridis. First, ladybirds leave feeding sites and orientate to the macrosite, defined as the visual feature on the horizon towards which ladybirds fly to aggregate. Second, the beetles alight on the surface of the macrosite. Third, they choose to stay or not according to the substrate features. Fourth, they search for a microsite, shelter wherein ladybirds take refuge to overwinter. Finally, they settle at the microsite. The first two stages have well documented behaviours (Voronin, 1965; Nalepa et al., 2000; 
Zenyoji, 2008). Harmonia axyridis shows a hypsotactic behaviour (i.e. moving towards prominent objects on the horizon) (Obata, 1986). It also shows a clear preference for visually contrasting elements (Nalepa et al., 2005). However, information about factors influencing the microsite choice is lacking. Some authors have suggested the use of volatile compounds in the aggregation process of ladybirds. According to al Abassi et al. (1998), pyrazines could be involved in this phenomenon. Indeed, they found an attractantarrestant response of the seven spotted ladybird, Coccinella septempunctata L., towards a 2-methoxypyrazine compound. Brown et al. (2006) suggested that (-)- $\beta$-caryophyllene could be a component of the aggregation pheromone of $H$. axyridis, as these authors documented the emission of this sesquiterpene by overwintering individuals. Subsequently, Verheggen et al. (2007) demonstrated the attractive and aggregative potential of this compound on $\mathrm{H}$. axyridis. On the other hand, Nalepa et al. (2000) put forth the assumption of the use of non volatile molecules in aggregation, which could explain why $H$. axyridis is observed in the same overwintering microsites from 1 year to another.

In this work, we have tested this hypothesis, that $H$. axyridis uses non-volatile compounds to select its overwintering sites: we have performed both chemical and behavioural analyses to examine this possibility.

\section{Materials and methods}

\subsection{Chemical analyses}

\subsubsection{In situ collection of secretions}

Material for chemical analyses was collected in infested dwellings situated in the vicinity of Gembloux (Belgium) during the winters of 2009 and 2010. The ladybirds were collected in a small container by delicately brushing the cluster using a pencil to prevent haemolymph release. The substrate where they had gathered was rubbed with approximately $0.15 \mathrm{~g}$ of dry quartz wool (fibre size of $2-12 \mu \mathrm{m}$ - FilterService S.A., Eupen, Belgium). This material was chosen for its abrasive and inert properties. No solvent was used in order to avoid contaminating our collections with components coming from paint and/or wallpaper. The chemicals collected on the quartz wool were directly extracted into $1 \mathrm{ml}$ of $n$-hexane (HPLC grade, 95\% purity - Fisher Scientific, Loughborough, Leicestershire UK) and this extract was used for chemical analyses.

\subsubsection{Identification of the chemicals}

Compounds from the collected material were identified by gas chromatography-mass spectrometry (GC-MS). This analysis was performed by injecting $1 \mu \mathrm{l}$ of the stored $n$-hexane extract on an Agilent Technologies 6890N Network GC System equipped with a HP-5 (5\% phenyl/95\% methylsiloxane) column (30 $\mathrm{m} \times 0.25 \mathrm{~mm}$ I.D.; film thickness $0.25 \mu \mathrm{m}$ ) coupled to an Agilent 5973 Network Mass Selective Detector. The operating conditions were: split ratio of $20: 1$, injector at $300{ }^{\circ} \mathrm{C}$; carrier gas: helium at $1.7 \mathrm{ml} / \mathrm{min}$; temperature program: from $40^{\circ} \mathrm{C}$ (held during $2 \mathrm{~min}$ ) to $320^{\circ} \mathrm{C}$ at $10^{\circ} \mathrm{C} / \mathrm{min}$ with a final hold of $10 \mathrm{~min}$ at $320^{\circ} \mathrm{C}$. The mass spectra were recorded in the electron impact mode at $70 \mathrm{eV}$ (source temperature at $230^{\circ} \mathrm{C}$, transfer line at $320^{\circ} \mathrm{C}$, scanned mass range: $40-500 \mathrm{~m} / \mathrm{z}$ ). The detected peaks were identified by their characteristic fragmentation patterns. The identification of saturated compounds was then confirmed by injection of $n$-alkanes standard (from $\mathrm{C}_{9}$ to $\mathrm{C}_{40}$ ).

To identify the double bonds position of monounsaturated compounds, an epoxidation using $m$-perchlorobenzoic acid was performed (Mallet et al., 1985). This reaction leads to the synthesis of an epoxide at the double bond position, causing the molecule break at this place in the mass spectrometer, thus giving two characteristic mass fragments. It was performed on approximately $500 \mu \mathrm{g}$ of collected material recovered from the $n$-hexane solution. The $n$-hexane was evaporated at $50{ }^{\circ} \mathrm{C}$ in a Büchi bath. Two hundred microlitres of chloroform (99\% purity - Merck KGaA, Darmstadt, Germany) and $200 \mu \mathrm{l}$ of a chloroformic solution of acid $m$-perchlorobenzoic ( $25 \mathrm{mg} / \mathrm{ml}$ ) (p.a. - Acrōs organics, New Jersey, USA) were then added to the residue. The resulting blend was continuously agitated for $2 \mathrm{~h}$. After this, $200 \mu \mathrm{l}$ of an aqueous solution of sodium hydrogenosulfite $(50 \mathrm{mg} / \mathrm{ml}$ ) (p.a. - Acrōs organics, New Jersey, USA) and sodium hydrogenocarbonate $(50 \mathrm{mg} / \mathrm{ml})$ (p.a. Carlo Erba, Milano, Italy) were added, followed by $1 \mathrm{ml}$ of chloroform. The resulting mixture was rinsed twice with $1 \mathrm{ml}$ of distilled water and dried using anhydrous sodium sulphate (Merck KGaA, Darmstadt, Germany). Finally, the sample was kept at $-18^{\circ} \mathrm{C}$ until GC-MS analysis.

\subsubsection{Quantification of the chemicals in the collected material}

Quantification of constituent components was carried out using a Thermo Trace GC Ultra (Thermo Electron Corporation) equipped with a flame ionisation detector (FID) and a Ph5 column $(5 \mathrm{~m} \times 0.1 \mathrm{~mm} \times 0.1 \mu \mathrm{m})$. The injection was performed with a split ratio of $20: 1$. The carrier gas was helium $(0.5 \mathrm{ml} / \mathrm{min})$. The temperature program was $40^{\circ} \mathrm{C}$ for $30 \mathrm{~s}$, then an increase of $60^{\circ} \mathrm{C} / \mathrm{min}$ to $310^{\circ} \mathrm{C}$, which was held for $1 \mathrm{~min}$. The use of a fast GC allowed us to reduce the time required for analyses and a FID detector $(300 \mathrm{~Hz})$ was chosen because of the stability of the signal through analyses. Compounds have been quantified with $n$-nonadecane as internal standard (IS) $(22 \mu \mathrm{g} / \mathrm{ml})$, this compound being absent in the extracts.

\subsubsection{Comparison with chemicals deposited by ladybirds while walking}

During our observations in infested dwellings, we noticed that ladybirds seem to follow a trail to join aggregations. It is known that ladybirds leave hydrocarbon tracks as they walk (e.g. Kosaki and Yamaoka, 1996): we therefore also analysed chemicals left by overwintering $H$. axyridis while walking. To do so, 40 ladybirds from infested houses were introduced into a glass Petri dish previously cleaned with norvanol (ether-denatured ethanol, 93\% purity - VWR International, Haasrode, Belgium) and were allowed to mark it by walking for a period of $24 \mathrm{~h}$. These Petri dishes were kept at $22 \pm 1{ }^{\circ} \mathrm{C}$, so we obtained only small aggregations over the $24 \mathrm{~h}$. After this length of time, ladybirds were picked up and the marking was collected with quartz wool impregnated with $n$ hexane. The chemicals collected from one Petri dish were dissolved in $1 \mathrm{ml}$ of $n$-hexane. The resulting blend will subsequently be referred to as "walking extract". This walking extract was then analysed as previously described by GC-MS for identification purposes and by Thermo Trace GC Ultra for quantification ones.

To compare the two chemical extracts, the one coming from microsites and the one deposited by ladybirds while walking, a multivariate analysis of variance (MANOVA) was performed using Minitab $^{\circledR}$ 15.1.1.0. (State College, Pennsylvania, USA $-\alpha=5 \%$ ). Given that the replicate number was low, the Pillai's test was used in order to reduce the risk of type I errors (Morrison, 2005). This statistical analysis was carried out on normalised data, obtained by summing the peak areas of all analysed compounds and calculating the relative proportion of each variable.

\subsection{Behavioural experiments}

\subsubsection{Biological material}

The ladybirds used in all behavioural experiments were collected in infested dwellings located in the region of Gembloux (Belgium) during the winters of 2009 and 2010. Adults were placed in $36 \times 15 \times 8 \mathrm{~cm}$ aerated plastic boxes for 20 days at most, until 
the beginning of the test. In order to maintain them under aggregation conditions, they were kept in the dark, at $15 \pm 1^{\circ} \mathrm{C}$ without any food or water.

\subsubsection{Aggregation assays}

The experimental set-up consisted of a glass Petri dish (diameter: $18 \mathrm{~cm}$, height: $4 \mathrm{~cm}$ ), in which the inside walls were covered with a strip of brass wire mesh $(90 \times 90$ mesh - Innopress Sarl, Touvois, France) previously cleaned with norvanol. Such an experimental design was used further to previous observations showing that $H$. axyridis prefers to aggregate vertically and especially on this brass substrate. Twenty ladybirds (males and females not being differentiated) were introduced inside the arena and were left for $24 \mathrm{~h}$ to aggregate. After that time and $24 \mathrm{~h}$ before the beginning of the test, ladybirds were removed and the metal strip was cleaned with norvanol except for the area where the ladybirds had aggregated. Glass arenas were cleaned up before the beginning of the experiment with the liquid detergent RBS T 105 (Chemical Products R. Borghgraef, Brussels, Belgium) and norvanol to eliminate any secretion previously left by other ladybirds. The metal strip was then replaced in the Petri dish.

Ten ladybirds, different from the first 20, were released in the centre of the Petri dish and their position was recorded after $30 \mathrm{~min}, 1,3,5$ and $8 \mathrm{~h}$. A low number of ladybirds was used during the experiment with the intention of avoiding any effect of potential trails from ladybirds walking in the dish. Seven areas were defined inside the glass arena: six identical portions (except for the presence of chemicals in one of them) and a $4 \mathrm{~cm}$ diameter circle in the centre, defining a neutral area (Fig. 1). Twenty-eight replicates were performed, with a Petri dish constituting one repetition. To avoid directional effects, seven repetitions were carried out by orienting the area containing the chemicals towards each main point of the compass (north, south, east and west). The entire experiment, including the depositing of chemicals by ladybirds, was carried out in a growth chamber at $15 \pm 1^{\circ} \mathrm{C}$, with a 9-h light photoperiod and $55 \pm 5 \% \mathrm{RH}$. At the end of the test, any compounds present on the portion of the grid where ladybirds had gathered were collected and analysed by GC-MS in order to compare them with the chemicals collected in infested dwellings. A MANOVA was then performed on these two data sets using Minitab ${ }^{\circledR}$ 15.1.1.0. (State College, Pennsylvania USA $-\alpha=5 \%$ ). Again, the Pillai's test was used to prevent false negatives (Morrison, 2005) and the statistical test was carried out on normalised data.

To verify that the observed behaviour was due to the compounds collected in houses, the experiment was repeated with $500 \mu \mathrm{l}$ of the extract from infested dwellings (corresponding to approximately $58.4 \mu \mathrm{g}$ of compound mixture expressed as $\mathrm{C}_{19}$ equivalent), on $1 / 20$ th of the steel strip. This quantity of blend per unit area was in accordance with the average amount evalu-

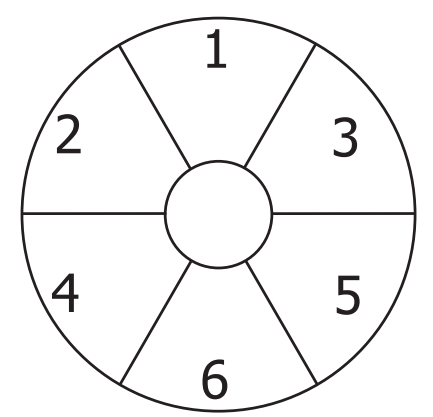

Fig. 1. Experimental set-up for chemotactic-choice test involving microsite extracts. Diagram of the experimental set-up used to study the behaviour of $H$. axyridis towards the chemicals collected in microsites, area 1 containing the extract, areas 2 until 6 being controls and the central area being neutral. ated as naturally occurring in aggregation sites $(5.56 \pm 1.53 \mu \mathrm{g} /$ $\mathrm{cm}^{2}$ ). To obtain this data, a $7 \mathrm{~cm}^{2}$ area of 10 different microsites were scrubbed for $30 \mathrm{~s}$. In order to collect all the compounds, this operation was performed three times. The methods of collection and quantification of the compounds were the same as described above (see Sections 2.1.1. and 2.1.3).

Results of the two aggregation experiments were analysed by adjusting a generalised linear mixed model (GLMMz) to the observed counts in the marked area versus the unmarked ones. To take into account the non-independence of the different observation times, repetitions were introduced as a random effect, with a fixed time effect. A binomial error family was used for the model, with a logit link between the linear part of the model and the estimated probabilities. As only one of the six lateral areas was marked, we tested the null hypothesis of no effect of the deposit of chemical compounds by comparing the observed probability of presence in the marked area against the theoretical value of one sixth, corresponding to a random choice, using the coefficients of the adjusted GLMMz model. The individuals located in the central area at each observation time were not included in the analysis. GLMMz analysis was performed with $\mathrm{R}$ statistical software, $\mathrm{v}$. 2.13.0. and lme4 package v. 0.999375-40. Thereafter, the independence between individuals was tested by comparing the distribution obtained at $8 \mathrm{~h}$ in the marked area with a binomial theoretical distribution which should be observed when no interaction exists between individuals. This comparison was performed via a Chi-squared Goodness-of-fit Test (Minitab ${ }^{\circledR}$ 15.1.1.0., State College, Pennsylvania USA $-\alpha=5 \%, 1 \mathrm{df}$ ).

\subsubsection{Walking assays}

The behaviour of the multicoloured Asian ladybirds towards the marking deposited by congeners while walking was tested in a Yshaped glass tube (height: $10 \mathrm{~cm}$, diameter: $1 \mathrm{~cm}$ ). This device was entirely cleaned with norvanol prior the beginning of assays. Two ladybirds coming from an aggregation site were introduced in the Y-shaped tube and left inside for $20 \mathrm{~h}$. One of the two tube arms was previously obstructed in order that only one arm and the base of the tube would be marked. The choice between the two arms was then observed for individual male and female ladybirds, in total for 50 males and 50 females. To avoid any directional bias, the direction of the marked arm was switched from one replicate to another. The experiment length was $3 \mathrm{~min}$, this time being sufficient for the majority of individuals to explore the entire setup. Each time a ladybird chose the side free from chemical compounds, the arm was cleaned with norvanol in order to avoid influence on the choice of the following individuals. Control assays, conducted in such a Y-shaped glass tube presenting one arm coated with norvanol, were preliminary performed to verify that this solvent has no effect on the behaviour of $H$. axyridis. On the other hand, it was impossible to eliminate the marking deposited by ladybirds in the arm containing the chemicals. However, the crossing of $H$. axyridis in the marked arm only reinforces the blend and the quantity of compounds deposited by a ladybird is presumably negligible in comparison with the one already present in the set-up, given the short time of an experiment ( $3 \mathrm{~min}$ ) compared to the initial marking time of $20 \mathrm{~h}$.

In order to check if the walking extract ( $c f$ Section 2.1.4) was involved in the observed behaviour, the Y-shaped glass tube test was repeated by depositing $500 \mu \mathrm{l}$ of this blend (being approximately equivalent to $20.85 \mu \mathrm{g}$ of compounds in $\mathrm{C}_{19}$ equivalent). Again, the used quantity was set up according to the natural conditions observed in preliminary work $\left(0.63 \mu \mathrm{g} / \mathrm{cm}^{2}\right)$ and the tube was cleaned with norvanol before the beginning of the test, as was the non-marked arm when it was chosen by a ladybird. In this experiment, 40 males and 40 females were tested. 
We have often observed naturally overwintering ladybirds starting to move in infested dwellings when temperatures increase or reforming a cluster when they are disturbed; furthermore, the ladybirds used in this experiment readily moved about the experimental set-up. Thus, there appears to be no obvious atypical effects resulting from the use of ladybirds that have already aggregated for overwintering.

For the two walking assays and for the control, a Chi-squared Goodness-of-fit Test (Minitab ${ }^{\circledR}$ 15.1.1.0., State College, Pennsylvania, USA - $\alpha=5 \%, 1 \mathrm{df}$ ) was used to compare the observed frequencies with expected ones (50\% of ladybirds choosing each arm). Afterwards, a Chi-square Test of Independence (Minitab ${ }^{\circledR}$ 15.1.1.0., State College, Pennsylvania USA $-\alpha=5 \%, 1 \mathrm{df}$ ) was performed to compare the behaviour of males with that of females. These tests were carried out on the observed absolute numbers. Ladybirds which did not make a choice within the $3 \mathrm{~min}$ were not included in the statistical test.

\section{Results}

\subsection{Chemical analyses}

The GC-MS investigations revealed that the two collected extracts: the microsite one and the walking one are made up of the same compounds, which were identified as hydrocarbons (Table 1). Chemical analysis detected 5 saturated, 4 mono-unsaturated and 3 di-unsaturated homologues. The two hentriacontenes were considered as one compound (peak 12) as the distinction between the two peaks was not always clear in fast-GC chromatograms.

However, the two extracts are quantitatively different (MANOVA: $F_{9,2}=100.343, P=0.010$ ) (Fig. 2). Indeed, overall, microsite extracts predominantly contain saturated compounds (64.83 $\pm 29.42 \%$ ) (mean \pm SD), whereas walking extracts contain a higher proportion of unsaturated hydrocarbons $(73.18 \pm 14.36 \%$ ) (mean \pm SD).

\subsection{Aggregation assays}

GLMMz performed on the distributions of ladybirds between the various areas of the experiment testing the microsite extracts, showed after $3 \mathrm{~h}$ a significant difference in favour of the area containing the compounds, both when the blend was deposited by ladybirds and by the experimenter. Table 2 presents these results along with the mean percentage of ladybirds observed in each of the six areas for each observation time. The data are given as percentages to facilitate their reading but statistical analyses were performed on the absolute counts. The observed differences are expressed by a greater mean number of ladybirds in the marked area than would be expected by chance (Table 2). When considering only control areas, no such tendency is observed for the areas adjacent to the marked area (i.e. areas 2 and 3) (Table 2). Moreover, chemical and statistical analyses revealed that the two blends (the one deposited by ladybirds themselves and the one collected in infested dwellings) were similar, both qualitatively and quantitatively (MANOVA: $F_{12,1}=11.47, P=0.227$ ).

Fig. 3 shows the comparison between the distribution of ladybirds, in the area containing the microsite extract, after $8 \mathrm{~h}$ of experimentation and a binomial theoretical distribution. Among the 280 ladybirds tested in each experiment (10 ladybirds $\times 28$ replicates), 125 and 97 were observed in the area containing the chemicals deposited by ladybirds and by the experimenter, respectively. Two theoretical binomial distributions were then generated with an estimated probability respectively of $0.45(125 / 280)$ and $0.35(97 / 280)$ that an individual occupies the marked area at this observation time. The Chi-square Goodness-of-fit Test revealed that the distributions obtained at $8 \mathrm{~h}$ were different from the binomial ones both for the compounds deposited by ladybirds $\left(\chi_{(1 d f)}^{2}=50.02, P<0.001\right)$ (Fig. 3(a)) and for that deposited by the experimenter $\left(\chi_{(1 d f)}^{2}=9.34, P=0.009\right)$ (Fig. $3(\mathrm{~b})$ ).

\subsection{Walking assays}

When the track was deposited by ladybirds in the Y-shaped glass tube, 33 females $\left(\chi_{(1 d f)}^{2}=5.12, P=0.024\right)$ and 38 males $\left(\chi_{(1 d f)}^{2}=13.52, P<0.001\right)$, out of the 50 individuals tested for each sex, chose the arm containing the blend. When the extract was artificially deposited by the experimenter, 31 females $\left(\chi_{(1 d f)}^{2}=\right.$ $12.1, P=0.001)$ and 30 males $\left(\chi_{(1 d f)}^{2}=10, P=0.002\right)$, out of the 40 ladybirds tested for each sex, chose the marked arm. No significant difference was observed between the behaviour of males and females either for the test using track deposited by $H$. axyridis $\left(\chi_{(1 d f)}^{2}=1.214, P=0.271\right)$ or for the test with the artificially deposited chemicals $\left(\chi_{(1 d f)}^{2}=0.069, P=0.793\right)$. Moreover, no attractive nor repellent effect of the norvanol was observed neither for males $\left(\chi_{(1 d f)}^{2}=0.4, P=0.527\right)$ nor females $\left(\chi_{(1 d f)}^{2}<0.001, P>0.999\right)$.

\section{Discussion}

This study highlights the use of long-chain hydrocarbons by the multicoloured Asian ladybirds during overwintering aggregation. First, overwintering $H$. axyridis individuals use conspecific

Table 1

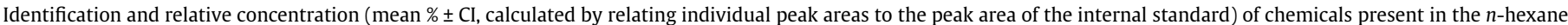

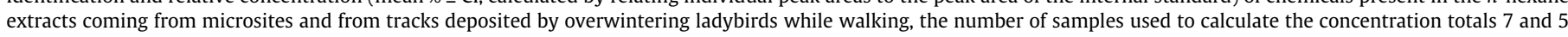
for microsite extracts and walking extracts, respectively.

\begin{tabular}{|c|c|c|c|c|c|c|}
\hline Peak number & Name & $A b b^{a}$ & $\mathrm{RT}^{\mathrm{b}}$ & $\mathrm{M}^{+\mathrm{c}}$ & Microsite extracts & Walking extracts \\
\hline 1 & $n$-Tricosane & $n C_{23}$ & 22.721 & 324 & $38.58 \pm 18.74$ & $13.74 \pm 2.88$ \\
\hline 2 & n-Tetracosane & $n \mathrm{C}_{24}$ & 23.546 & 338 & $2.32 \pm 2.97$ & $0.67 \pm 1.21$ \\
\hline 3 & 9-Pentacosene & $C_{25}: 1$ & 24.160 & 350 & $6.51 \pm 6.12$ & $16.58 \pm 3.18$ \\
\hline 4 & n-Pentacosane & $n \mathrm{C}_{25}$ & 24.345 & 352 & $16.31 \pm 8.24$ & $6.47 \pm 4.34$ \\
\hline 5 & Heptacosadiene & $\mathrm{C}_{27}: 2$ & 25.614 & 376 & $1.25 \pm 1.62$ & $2.22 \pm 2.25$ \\
\hline 6 & 9-Heptacosene & $\mathrm{C}_{27}: 1$ & 25.694 & 378 & $5.19 \pm 4.33$ & $18.89 \pm 2.58$ \\
\hline 7 & n-Heptacosane & $n \mathrm{C}_{27}$ & 25.857 & 380 & $4.13 \pm 3.89$ & $3.02 \pm 3.27$ \\
\hline 8 & Nonacosadiene & $C_{29}: 2$ & 27.000 & 404 & $8.64 \pm 9.00$ & $14.29 \pm 8.33$ \\
\hline 9 & 9-Nonacosene & $\mathrm{C}_{29}: 1$ & 27.121 & 406 & $3.20 \pm 2.10$ & $8.35 \pm 1.76$ \\
\hline 10 & n-Nonacosane & $n \mathrm{C}_{29}$ & 27.275 & 408 & $3.49 \pm 5.50$ & $1.45 \pm 2.27$ \\
\hline 11 & unknown & & 27.481 & & $1.58 \pm 0.74$ & $1.47 \pm 0.73$ \\
\hline $12 \mathrm{a}$ & Hentriacontadiene & $C_{31}: 2$ & 28.311 & 432 & $7.23 \pm 7.31$ & $9.47 \pm 3.43$ \\
\hline $12 b$ & Hentriacontadiene & $C_{31}: 2$ & 28.359 & 432 & & \\
\hline 13 & 9-Hentriacontene & $C_{31}: 1$ & 28.454 & 434 & $1.58 \pm 0.98$ & $3.37 \pm 0.81$ \\
\hline
\end{tabular}

\footnotetext{
a Abbreviation of hydrocarbon name.

b Retention time.

c Molecular ion.
} 


\section{(a) microsite extracts}

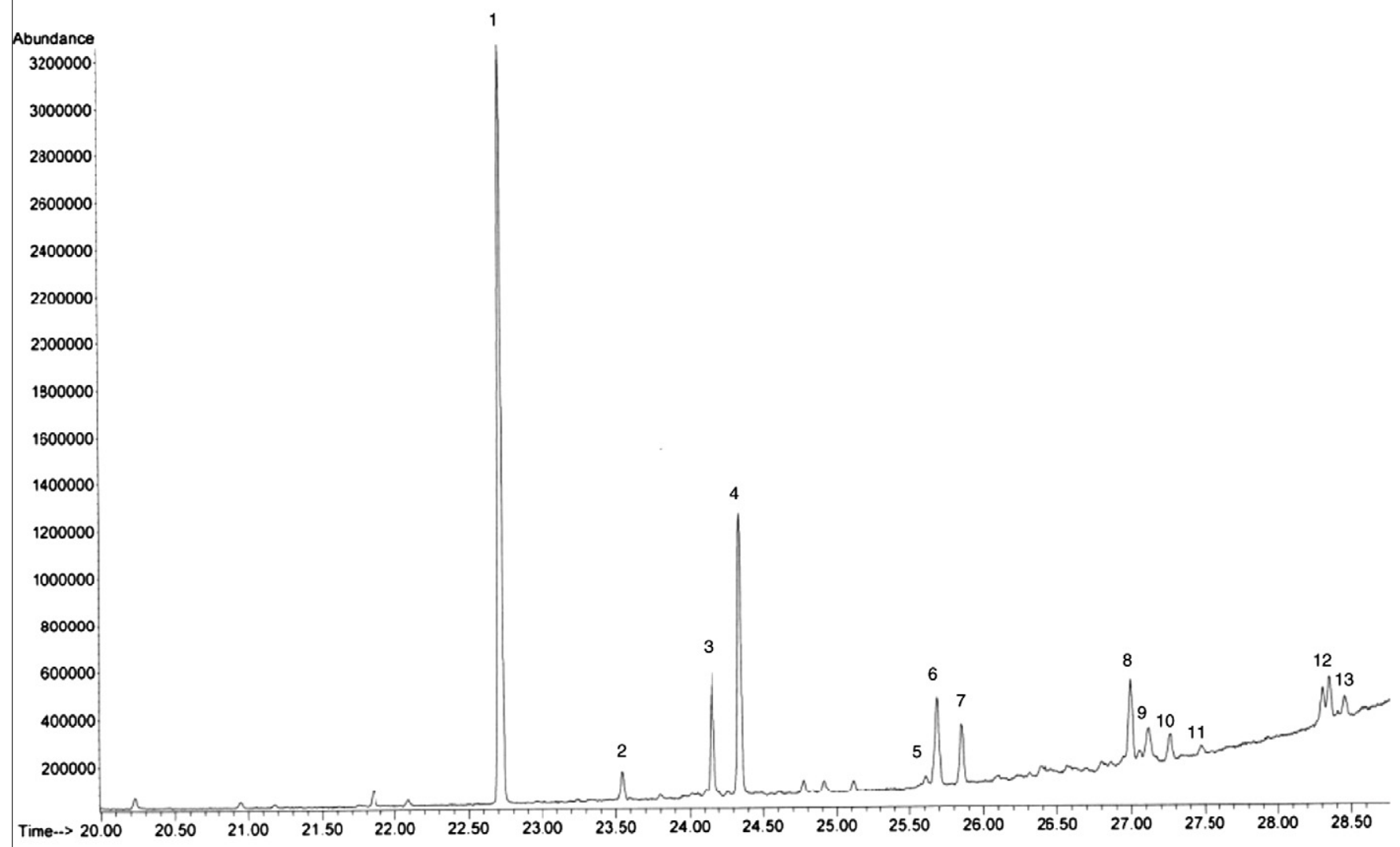

\section{(b) walking extracts}

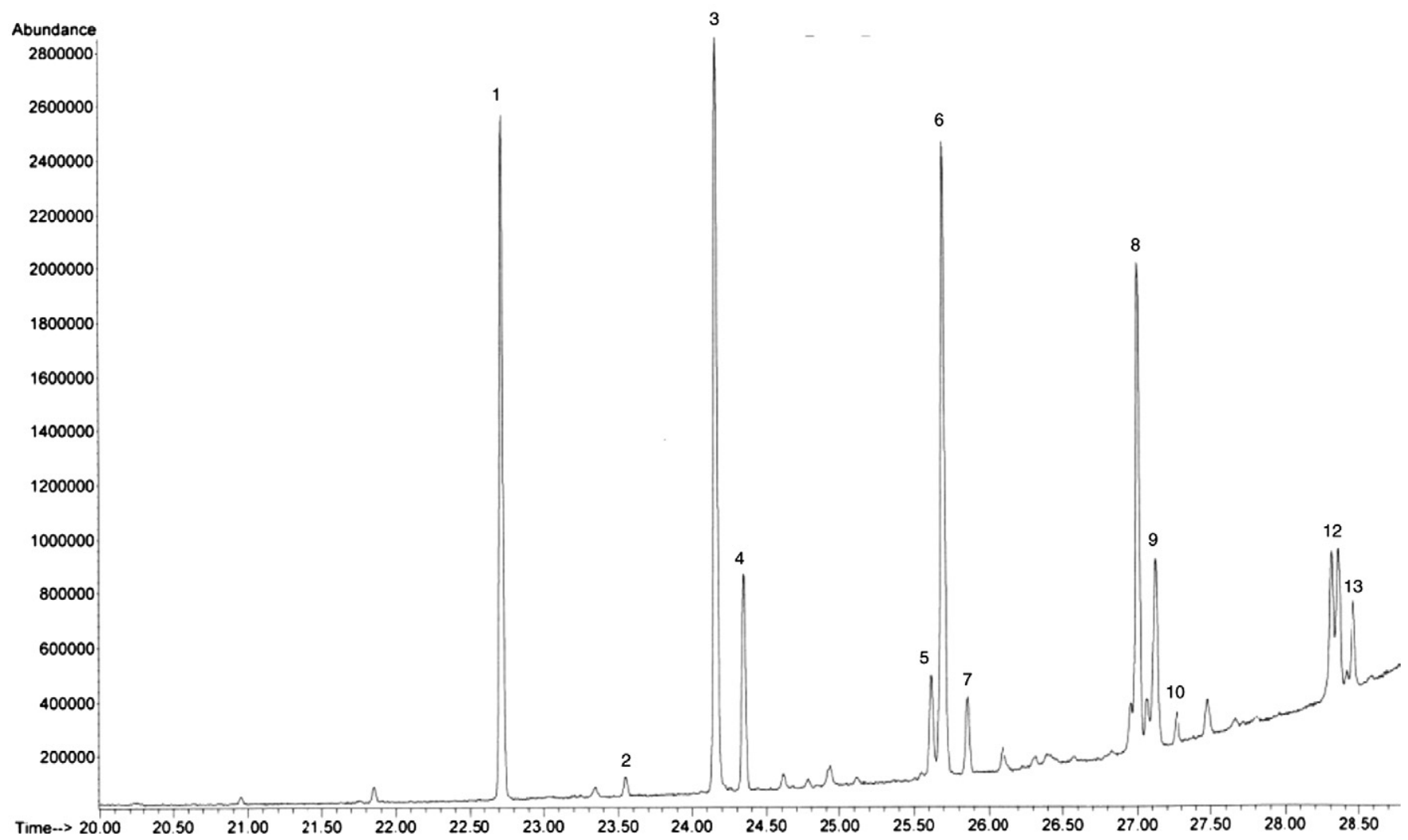

Fig. 2. Gas chromatograms. Comparisons between GC-MS chromatograms of extracts coming from (a) overwintering sites (microsite extracts) and (b) tracks left by overwintering H. axyridis while walking (walking extracts). 
Table 2

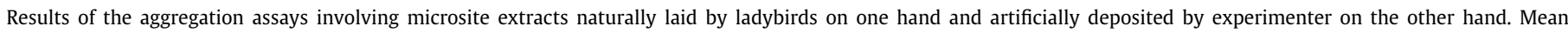

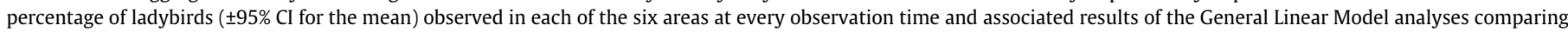

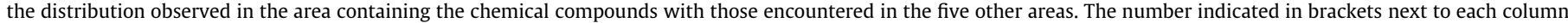
title corresponds to the number allocated to each area of the experimental set-up ( $c f$ Fig. 1).

\begin{tabular}{|c|c|c|c|c|c|c|c|c|}
\hline Type of marking & Time & Area with blend (1) & Control 1 (2) & Control 2 (3) & Control 3 (4) & Control 4 (5) & Control 5 (6) & $P$ value \\
\hline \multirow[t]{5}{*}{ Natural } & $30 \mathrm{~min}$ & $27.54 \pm 5.27$ & $18.48 \pm 4.58$ & $11.96 \pm 3.83$ & $17.75 \pm 4.51$ & $12.68 \pm 3.93$ & $11.59 \pm 3.78$ & \\
\hline & $1 \mathrm{~h}$ & $28.88 \pm 5.34$ & $16.25 \pm 4.34$ & $16.97 \pm 4.42$ & $14.80 \pm 4.18$ & $12.27 \pm 3.86$ & $10.83 \pm 3.66$ & \\
\hline & $3 \mathrm{~h}$ & $40.43 \pm 5.78$ & $11.19 \pm 3.71$ & $12.64 \pm 3.91$ & $15.16 \pm 4.22$ & $12.27 \pm 3.86$ & $8.30 \pm 3.25$ & $* *$ \\
\hline & $5 \mathrm{~h}$ & $46.38 \pm 5.88$ & $10.87 \pm 3.67$ & $11.59 \pm 3.78$ & $8.33 \pm 3.26$ & $17.39 \pm 4.47$ & $5.43 \pm 2.67$ & $* * *$ \\
\hline & $8 \mathrm{~h}$ & $45.68 \pm 5.86$ & $12.59 \pm 3.90$ & $11.87 \pm 3.80$ & $11.87 \pm 3.80$ & $11.51 \pm 3.75$ & $6.47 \pm 2.89$ & $* * *$ \\
\hline \multirow[t]{5}{*}{ Artificial } & $30 \mathrm{~min}$ & $19.40 \pm 4.73$ & $17.91 \pm 4.59$ & $16.79 \pm 4.48$ & $16.04 \pm 4.39$ & $18.66 \pm 4.66$ & $11.19 \pm 3.77$ & \\
\hline & $1 \mathrm{~h}$ & $18.66 \pm 4.66$ & $16.04 \pm 4.39$ & $16.79 \pm 4.48$ & $13.43 \pm 4.08$ & $20.15 \pm 4.80$ & $14.93 \pm 4.27$ & \\
\hline & $3 \mathrm{~h}$ & $26.62 \pm 5.34$ & $15.59 \pm 4.38$ & $14.45 \pm 4.25$ & $12.55 \pm 4.00$ & $17.49 \pm 4.59$ & $13.31 \pm 4.11$ & * \\
\hline & $5 \mathrm{~h}$ & $26.77 \pm 5.29$ & $18.59 \pm 4.65$ & $16.73 \pm 4.46$ & $11.52 \pm 3.82$ & $15.99 \pm 4.38$ & $10.41 \pm 3.65$ & * \\
\hline & $8 \mathrm{~h}$ & $35.93 \pm 5.72$ & $18.15 \pm 4.60$ & $9.26 \pm 3.46$ & $8.89 \pm 3.39$ & $18.52 \pm 4.63$ & $9.26 \pm 3.46$ & $* * *$ \\
\hline
\end{tabular}

* Indicate statistical differences with $P<0.05$.

** Indicate statistical differences with $P<0.01$.

*** Indicate statistical differences with $P<0.001$.
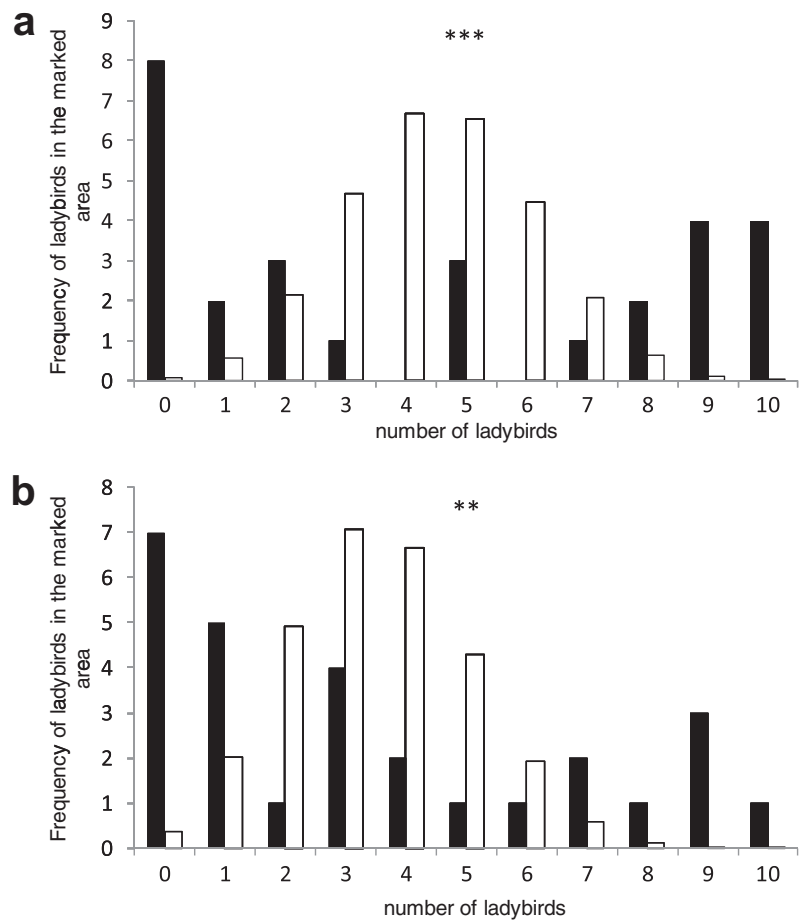

Fig. 3. Distribution of ladybirds in the marked area at 8 hours. Observed (black) and theoretical binomial (white) distributions of $H$. axyridis at the observation time of 8 hours, in the marked area of the chemotactic-choice experiment testing the microsite extracts, using the chemicals deposited by overwintering ladybirds on one hand (a) and placed by the experimenter on the other hand (b) ( ${ }^{* *}$ and ${ }^{* * *}$ indicating statistical differences between observed and theoretical distributions, with $P<0.01$ and $P<0.001$ respectively).

hydrocarbons as microsite indicators. Our Y-shaped tube assays show that aggregating ladybirds preferentially orientate towards the arm which contained these chemical compounds. It follows that the role of this marking may be to orientate conspecifics towards aggregation places, i.e. after reaching macrosite, ladybirds would follow this marking leading to the microsite. The first ladybirds would use tracks left by conspecifics the previous year. The blend may change to some extent over time but it contains certain very stable components, notably saturated hydrocarbons (Jamart et al., 2009), which could be used by the first individuals to orientate towards the microsite. Since area marks probably originates from footprints laid passively (Kosaki and Yamaoka, 1996), these first individuals would refresh and reinforce the marking while walking around the microsite. This could then facilitate the orientation of the later individuals and beetles the following year. The intensity of footprints around an overwintering site is directly related to the density of their conspecifics. Beetles could then assess the potential interest of a site through this parameter. Such a behaviour has already been observed in the ant Lasius niger during its foraging (Devigne and Detrain, 2002, 2006).

Second, $H$. axyridis deposit a blend of hydrocarbons at their overwintering microsite. Behavioural tests show a clear preference of overwintering ladybirds for areas where those compounds are present (Table 2). Long-chain hydrocarbons are molecules of low volatility (Ozaki and Wada-Katsumata, 2010). They would then not be involved in the beetles' attraction but rather to ensure the cohesion of the aggregation. The fact that no greater number of ladybirds was observed in the areas adjacent to the one containing the blend confirms that the ladybirds have to be in contact with the hydrocarbons for the arrestant capacity of the compounds to work. On the other hand, the differences highlighted between the observed distributions and the theoretical binomial ones could be explained by tracks left by overwintering ladybirds when walking. If the observed distributions were binomial, the ladybirds would not be influenced by the presence of conspecifics and respond only to the deposited blends tested in the experiment. In this case, the distributions are different, meaning that individual behaviour could be influenced by other cues coming from congeners, being possibly additional markings including walking tracks and new deposits of "microsite hydrocarbons" elsewhere in the set-up, contact between conspecifics or volatiles.

Chemical analyses revealed that the two collected blends (the one deposited by ladybirds while walking and the one collected in aggregation microsites) are made up of the same hydrocarbons. But quantitative analyses revealed profile differences between the two extracts, the walking extract being richer in unsaturated compounds. The difference between the two markings might act as cues for particular behaviours: i.e. walking or stopping to aggregate. Moreover, the unsaturated compounds are less stable than saturated ones (Jamart et al., 2009). They could then be used by the ladybirds to evaluate the age of deposits, giving them information about the recentness of conspecific activity and thus about the suitability of a microsite.

Kosaki and Yamaoka (1996) highlighted the presence of hydrocarbons in ladybirds footprints and suggested their involvement in the adhesion of these insects on smooth surfaces. It follows that 
the hydrocarbons found on and around microsites do not seem come from active secretions but rather from passive contacts with $H$. axyridis bodies. The observation that the two extracts have different chemical profiles might be explained by variation of the cuticular profile of different parts of the body, as it is the case for the ant L. niger (Lenoir et al., 2009). Indeed, while walking, a ladybirds' abdomen does not contact the substrate whereas it does at the microsite (personal observations).

Several studies have confirmed the use of hydrocarbons in choosing a resting site or a nest in other insects including ants (Depickère et al., 2004; Lenoir et al., 2009), cockroaches (Rivault et al., 1998) and wasps (Butler et al., 1969; Jandt et al., 2005). In the Coccinellidae, hydrocarbons participate in the protection against intraguild predation and, to lesser extent, against cannibalism, in species recognition for mating and also in deterrence of females from ovipositing in a place where conspecific larvae are already present (Hemptinne and Dixon, 2000). Our results show for the first time the use of these compounds by a ladybird species in the localisation of a microsite to overwinter. The colonised overwintering sites may be used repeatedly over a number of years, therefore these cues could represent a long-term external memory for the location of previously used sites. This would be in accordance with the studies of Hills (1969) and Majerus (1997) highlighting the use of persistent molecules used by the two spotted ladybird, Adalia bipunctata (L.), to overwinter in the same sites year after year. It would be interesting to study what the lifetime of the markings described here is, in order to evaluate their role in this repeated use. They could also play an important role in the reorganization of ladybirds after disturbance, as individuals generally reform an aggregation in the same place after being disturbed (personal observations).

Infestations of $H$. axyridis in dwellings have become increasingly problematic (Goetz, 2006; Dutau and Rancé, 2008), causing both annoyance from their number and allergic reactions (Nakazawa et al., 2007; Sloggett et al., 2011). Until now, the only recommended way to avoid these problems was physical removal of the aggregation. The use of attractants in traps would be more appropriate to control populations of this invasive species and easier to handle for householders (Sloggett et al., 2011). The blends collected during these experiments could be used in the design of such a trap. However, the hydrocarbons identified here seem only to be perceived by the ladybirds on contact. In order to render a trap efficient, i.e. attracting $H$. axyridis ladybirds at long distances, volatile compounds would be required. The results presented here demonstrating the involvement of hydrocarbons in the aggregative process of $H$. axyridis, do not preclude the potential role of volatile compounds in this phenomenon. We are then currently investigating the potential use of volatiles organic compounds (VOC) by the multicoloured Asian ladybird by carrying out dynamic odours sampling (1) on natural aggregations in infested dwellings and (2) on artificial aggregations recreated in laboratory.

\section{Acknowledgements}

The authors thank Alice-Marie Buset for her technical assistance, and all the people who allowed us into their homes to conduct chemical collections.

Delphine Durieux and Christophe Fischer are financially supported by a $\mathrm{PhD}$ grant from the Fonds pour la formation à la Recherche dans l'Industrie et l'Agriculture (FRIA), Belgium. Axel Vandereycken and Emilie Joie are financially supported by the Service Public de Wallonie (SPW - DGO3, project No. D31-1197). The funding bodies had no role in study design, data collection and analysis, decision to publish, or preparation of the manuscript.

\section{References}

al Abassi, S., Birkett, M.A., Pettersson, J., Pickett, J.A., Woodcock, C.M., 1998. Ladybird beetle odour identified and found to be responsible for attraction between adults. Cellular and Molecular Life Sciences 54, 876-879.

Brown, A.E., Riddick, E.W., Aldrich, J.R., Holmes, W.E., 2006. Identification of (-)beta-caryophyllene as a gender-specific terpene produced by the multicolored Asian lady beetle. Journal of Chemical Ecology 32, 2489-2499.

Brown, P.M.J., Thomas, C.E., Lombaert, E., Jeffries, D.L., Estoup, A., Handley, L.J.L., 2011. The global spread of Harmonia axyridis (Coleoptera: Coccinellidae): distribution, dispersal and routes of invasion. BioControl 56, 623-641.

Butler, C.G., Fletcher, D.J.C., Watler, D., 1969. Nest-entrance marking with pheromones by honeybee, Apis mellifera L., and by a wasp Vespula vulgaris $\mathrm{L}$. Animal Behaviour 17, 142-147.

Depickère, S., Fresneau, D., Detrain, C., Deneubourg, J.L., 2004. Marking as a decision factor in the choice of a new resting site in Lasius niger. Insectes Sociaux 51, 243-246.

Devigne, C., Detrain, C., 2002. Collective exploration and area marking in the ant Lasius niger. Insectes Sociaux 49, 357-362.

Devigne, C., Detrain, C., 2006. How does food distance influence foraging in the ant Lasius niger: the importance of home-range marking. Insectes Sociaux 53, 46-55.

Dutau, G., Rancé, F., 2008. Nouveautés en allergologie. Revue Française d'Allergologie et d'Immunologie Clinique 48, S19-S26.

Goetz, D.W., 2006. Harmonia axyridis ladybug hypersensitivity in clinical allergy practice. Journal of Allergy and Clinical Immunology 117, S29.

Hemptinne, J.L., Dixon, A.F.G., 2000. Defence, oviposition and sex: semiochemical parsimony in two species of ladybird beetles (Coleoptera, Coccinellidae)? A short review. European Journal of Entomology 97, 443-447.

Hills, L.D., 1969. Biological pest control. Report 3. Henry Doubleday Research Associates, Essex.

Jamart, B., Bodiguel, J., Brosse, N., 2009. Chimie organique: les cours de Paul Arnaud, 18 th ed. Dunod, Paris.

Jandt, J.M., Curry, C., Hemauer, S., Jeanne, R.J., 2005. The accumulation of a chemical cue: nets-entrance trail in the German yellowjacket, Vespula germanica. Naturwissenschaften 92, 242-245.

Kosaki, A., Yamaoka, R., 1996. Chemical composition of footprints and cuticular lipids of three species of lady beetles. Japanese Journal of Applied Entomology and Zoology 40, 47-53.

Labrie, G., Coderre, D., Lucas, E., 2008. Overwintering strategy of multicolored Asian lady beetle (Coleoptera: Coccinellidae): cold-free space as a factor of invasive success. Annals of the Entomological Society of America 101, 860-866.

Lenoir, A., Depickere, S., Devers, S., Christides, J.P., Detrain, C., 2009. Hydrocarbons in the Ant Lasius niger: from the cuticle to the nest and home range marking. Journal of Chemical Ecology 35, 913-921.

Majerus, M.E.N., 1997. How is Adalia bipunctata (Linn.) (Coleoptera: Coccineliidae) attracted to overwintering sites? Entomologist 116, 212-217.

Mallet, G., Dimitriades, C., Ucciani, E., 1985. Apport des techniques de dérivatisation à la séparation des esters d'acides gras par chromatographie gazeuse capillaire. Revue Françaises des Corps Gras 32, 439-446.

McClure, M.S., 1987. Potential of the Asian predator, Harmonia axyridis Pallas (Coleoptera: Coccinellidae) to control Matsucoccus resinosae bean and godwin (Homopteran: Margarodidae) in the United States. Environmental Entomology $16,224-230$.

Morrison, D.F., 2005. Multivariate Statistical Methods, fourth ed. Brooks/Cole/ Thomson Learning, Pacific Grove.

Nakazawa, T., Satinover, S.M., Naccara, L., Goddard, L., Dragulev, B.P., Peters, E., Platts-Mills, T.A.E., 2007. Asian ladybugs (Harmonia axyridis): a new seasonal indoor allergen. Journal of Allergy and Clinical Immunology 119, 421-427.

Nalepa, C.A., Kennedy, G.G., Brownie, C., 2005. Role of visual contrast in the alighting behavior of Harmonia axyridis (Coleoptera: Coccinellidae) at overwintering sites. Environmental Entomology 34, 425-431.

Nalepa, C.A., Kidd, K.A., Hopkins, D.I., 2000. The multicolored Asian lady beetle (Coleoptera: Coccinellidae): orientation to aggregation sites. Journal of Entomological Science 35, 150-157.

Obata, S., 1986. Determination of hibernation site in the ladybird beetle, Harmonia axyridis Pallas (Coleoptera, Coccinellidae). Kontyu 54, 218-223.

Ozaki, M., Wada-Katsumata, A., 2010. Perception and olfaction of cuticular compounds. In: Blomquist, G.J., Bagnères, A.G. (Eds.), Insect Hydrocarbons, Biology, Biochemistry, and Chemical Ecology. Cambridge University Press, New York, pp. 207-221.

Rivault, C., Cloarec, A., Sreng, L., 1998. Cuticular extracts inducing aggregation in the German cockroach, Blattella germanica (L.). Journal of Insect Physiology 44, 909918.

Sloggett, J. Magro, A, Verheggen, F. ., Hemptinne, J.L, Hutchison, W.D., Riddick, E.W., 2011. The chemical ecology of Harmonia axyridis. BioControl 56, 643-661.

Verheggen, F.J., Fagel, Q., Heuskin, S., Lognay, G., Francis, F., Haubruge, E., 2007. Electrophysiological and behavioral responses of the multicolored Asian lady beetle, Harmonia axyridis Pallas, to sesquiterpene semiochemicals. Journal of Chemical Ecology 33, 2148-2155.

Voronin, K.E., 1965. Features of the formation of the overwintering population of Harmonia (Harmonia axyridis Pall.) - a predator of aphids in the Far East. Trudy Vsesoyuznogo nauchno-issledovatel'skogo Instituta Zashchity Rastenii 24, 228233

Zenyoji, S., 2008. Prediction of the time of flight for aggregation of Harmonia axyridis (Coleoptera Coccinellidae) in late autumn based on the concept of accumulation of exposure to low temperature. Japanese Journal of Entomology 11, 159-167. 